\title{
Screening of Brinjal (Solanum Melongena L.) Genotypes against Salinity
}

\author{
Javeed $\mathbf{Z}^{1}$, Ahmed $\mathbf{M}^{2}$, Mehdi $\mathrm{SM}^{3}$, Riaz $\mathrm{U}^{1}$, Sardar $\mathrm{A}^{4}$, Ehsan $\mathrm{M}^{5}$, \\ Saleem A ${ }^{6}$, Anum W7 ${ }^{7}$ Zulqadar SA $^{1}$ and Ahmed $\mathbf{Z}^{1}$ \\ ${ }^{1}$ Soil and Water Testing Laboratory for Research, Bahawalpur-63100, Pakistan \\ 2Department of Soil Science, University College of Agriculture \& Environmental Sciences, \\ The Islamia University of Bahawalpur \\ ${ }^{3}$ Directorate of Rapid Soil Fertility, Survey and Soil Testing Institute, Lahore, Pakistan \\ ${ }^{4}$ Department of Extension, Governament of Punjab, Hasilpur \\ ${ }^{5}$ Pesticides Residue Laboratory Kala Shah Kaku \\ ${ }^{6}$ Pesctides Quality Control Laboratory Bahawalpur \\ ${ }^{7}$ Wheat section, Regional Agricultural Research Institute, Bahawalpur
}

*Corresponding author: Umair Riaz, Soil and Water Testing Laboratory for Research, Bahawalpur Institute of Soil and Environmental Sciences, University of Agriculture Faisalabad, Pakistan, Tel: 3356021088; Email: umairbwp3@gmail.com

\section{Abstract}

The presence of salts in soil, underground water and surface water sources is the main cause of salinity that exacts economic and environmental issues like reduction in agriculture land, productivity, decline in quality of water and destruction of ecosystems. Brinjal is an important vegetable crop that provides valuable nutrition to human diet. Salinity, however is severely limiting its production in recent years. Therefore to evaluate the effect of salinity on different brinjal genotypes a hydroponic experiment was conducted, in context to screen-out the salinity tolerant variety. For this purpose, eight brinjal genotypes (Punjab Nagina, Twinkle, Black Beauty, Sandhya-F1, Adventa-303, Kalayan, Shamli and Adventa-306) were sown under three salinity levels viz; 3.0, 4.5, $6.0 \mathrm{dS} \mathrm{m}^{-1}$ along with a control treatment (normal irrigation water). The experiment was conducted in complete randomized design (CRD) factorial fashion with three replications. Adequate nutrient source (half strength Hoagland solution) was used with constant $\mathrm{pH}$ and the recorded data was analyzed statistically through LSD at 5\% level of probability. The results showed that increasing levels of salinity significantly decreased all growth and physiological parameters of brinjal genotype, except Sandhya-F1, which showed maximum tolerance to salinity. It was attributed through minimum decrease in shoot length, root length, shoot fresh weight, root fresh weight, shoot dry weight, root dry weight, carotenoid, chlorophyll a, chlorophyll b contents and membrane stability index of Sandhya-F1. The salinity tolerance in rest of the varieties was in the order of Adventa-306 > 


\section{Food Science and Nutrition Technology}

Twinkle > Punjab Nagina > Adventa-303 > Kalayan > Shamli > Black Beauty. So it may be suggested that brinjal variety Sandhya-F1 should be adopted by the farmers to enhance brinjal production under salt affected conditions.

Keywords: Brinjal; Genotypes; Salinity Stress; Tolerance

\section{Introduction}

The one of the most important limiting factor for the cultivation of brinjal in Pakistan is salinity. It is the most widespread problem, affecting approximately increased salinization of arable land is expected to have devastating global effects, resulting in $30 \%$ land loss within next 25 years and up to $50 \%$ by the middle of 21 st century [1]. Salt stress can directly or indirectly affect the physiological status of plants by disturbing their growth, development and productivity [2]. The uptake of high concentrations of toxic ions ( $\mathrm{Na}, \mathrm{Cl}$ etc.) inhibits the activities of several enzymes and disturbs plant metabolic activities [3]. These adverse effects of salinity for plants are mainly attributed due to the salt osmotic stress, specific ion toxicity, slat induced oxidative stress and imbalance in hormonal balance due to higher uptake of toxic ions and also salt induced nutrient deficiency [4]. Under salinity stress, growth inhibition is primary symptom in plants which leads to cellular disruption, inhibition of photosynthesis and oxidative disintegration [5]. It has also effect on many aspects of metabolism, anatomy and ultra-structure of plant cells [6].

Brinjal is also known as eggplant or aubergine belongs to the family "Solanaceae" and genus "solanum". It is a warm season's vegetable cultivated by the farmers all over the world. It originated in India and Pakistan, as Subcontinent people are used to grow brinjal since last 4000 years [7]. Now a day, it is extensively cultivated in Bangladesh, India, Pakistan, Nepal, U.A.E, Sri Lanka, Egypt and other warm countries of the world. World's statistics conceal that brinjal was second to potato and sweet potato in terms of production [8]. Worldwide production of brinjal was mainly in China, India, Egypt, Turkey and Indonesia with more than $85 \%$. Its area under cultivation was more than two million hectares with 35 million tons production [9]. Its sowing is done over 8767 hectares and produces 85965 tons annually. In Punjab it is sown over 4896 hectares and produces 58709 tons annually that indicates that Punjab is the major brinjal producing province of Pakistan [10].

Numerous aspects are responsible for the low production of brinjal crop in Pakistan. A number of biotic and abiotic stresses such as drought, salinity, alkalinity and pathogens decrease the crop yield. Crop damage by salinity in Pakistan is estimated about 880 million rupees annually which indicates that salinity is damaging extremely to the agricultural economy of Pakistan [11]. Seed germination and early seedling growth are the most sensitive stages which are stressed by salinity in most of the crops including brinjal [12]. Salt stress can directly or indirectly affect the physiological status of plants by disturbing their metabolism, growth, development and productivity [13].

Understanding about the salt tolerance of vegetable plants played a key role for management decisions and hence, to increase productivity [14]. There were many measures for investigating the levels of salt tolerance of varieties and species. Preferably, they should be simple to investigate and authorize the identification of salinity tolerance during seed germination or at the seedling stage. The methodology which was used should be precise, realistic, and comparatively rapid [15]. Brinjal was moderately sensitive to salinity Shahbaz, et al. [16] but more consideration to salinity stress is requisite in agricultural production with brinjal and its varieties. The determination of salt tolerance of brinjal varieties at the germination and seedling stages was essential $\mathrm{Wu}$, et al. [17] as it provided the prospect to make management decisions to reduce the influence of salinity. If the salt tolerance level of brinjal varieties was identified, then it minimized the salt injury during the more sensitive stages like germination and seedling stages. The objective of the present study was to investigate the response of some brinjal varieties to increasing level of salinity during the germination and seedling stages. Growth parameters like root length, shoot length, root fresh weight, shoot fresh weight, root dry weight, shoot dry weight, physiological parameters like chl a, chl b, carotenoid, membrane stability index and ionic balance in leaves and roots were the analyzed parameters.

\section{Material and Methods}

\section{Experimental Site}

The experiment was conducted at rain protected glass house of Department of Soil Science University College of 


\section{Food Science and Nutrition Technology}

Agriculture and Environmental Sciences, The Islamia University of Bahawalpur.

\section{Growth Conditions}

The sterilized seeds of selected brinjal genotypes were sown in sand culture for obtaining uniform seedlings. At two leaves stage, seedlings were transplanted into thermopole sheet floating on half strength Hoagland solution culture in 100L iron tubs. Salinity was created by using $\mathrm{NaCl}$. Aeration was given by bubbling air through aeration pumps. The solution was changed every week.

\section{Treatments}

The experiment comprised of following treatments

$\mathrm{T}_{1}$ control

$\mathrm{T}_{2} 3 \mathrm{dS} \mathrm{m}^{-1} \mathrm{E}$.C

$\mathrm{T}_{3} 4.5 \mathrm{dS} \mathrm{m}^{-1} \mathrm{E} . \mathrm{C}$

$\mathrm{T}_{4} 6 \mathrm{dS} \mathrm{m}^{-1} \mathrm{E} . \mathrm{C}$

\section{Plant Growth and Physiological Parameters}

After 4 weeks of stress, plants were collected for growth and physiological parameters like chlorophyll a and $b$ carotenoids and were determined. The fresh plant leaves were sampled after 50 days of transplanting for the determination of physio-biochemical attributes Chlorophyll a and $\mathrm{b}$, and carotenoids. The data regarding growth and physiological parameters was collected at harvest upon physiological maturity

\section{Statistical Analysis}

Experimental design was completely randomized design with three replications. Data obtained was analyzed statically by following the method of Steel.

\section{Results and Discussion}

\section{Root and Shoot Length}

The shoot and root length of brinjal genotypes was also decreased under salinity stress. On the basis of root length and shoot length "Sandhya F1" and "Adventa 306" were categorized as salt tolerant genotypes while "Black beauty" and "Shamli" were adversely affected by salinity so these are categorized as salt sensitive genotypes (Figures $1 \& 2$ ). Vahdati, et al. [2] stated that an increase in irrigation water salinity reduces plant height. Also plant height was significantly inhibited by salinity and treated plants reached $70 \%$ of the height of control plants Navaro, et al. [18] which agrees with the results of this study. Ladeiro [1] Determine that salinity affects the plant height significantly. The reason for reduction in growth may be due to poor nutrients and water transport to aerial parts, due to impaired and minimum root growth under salinity stress [19].

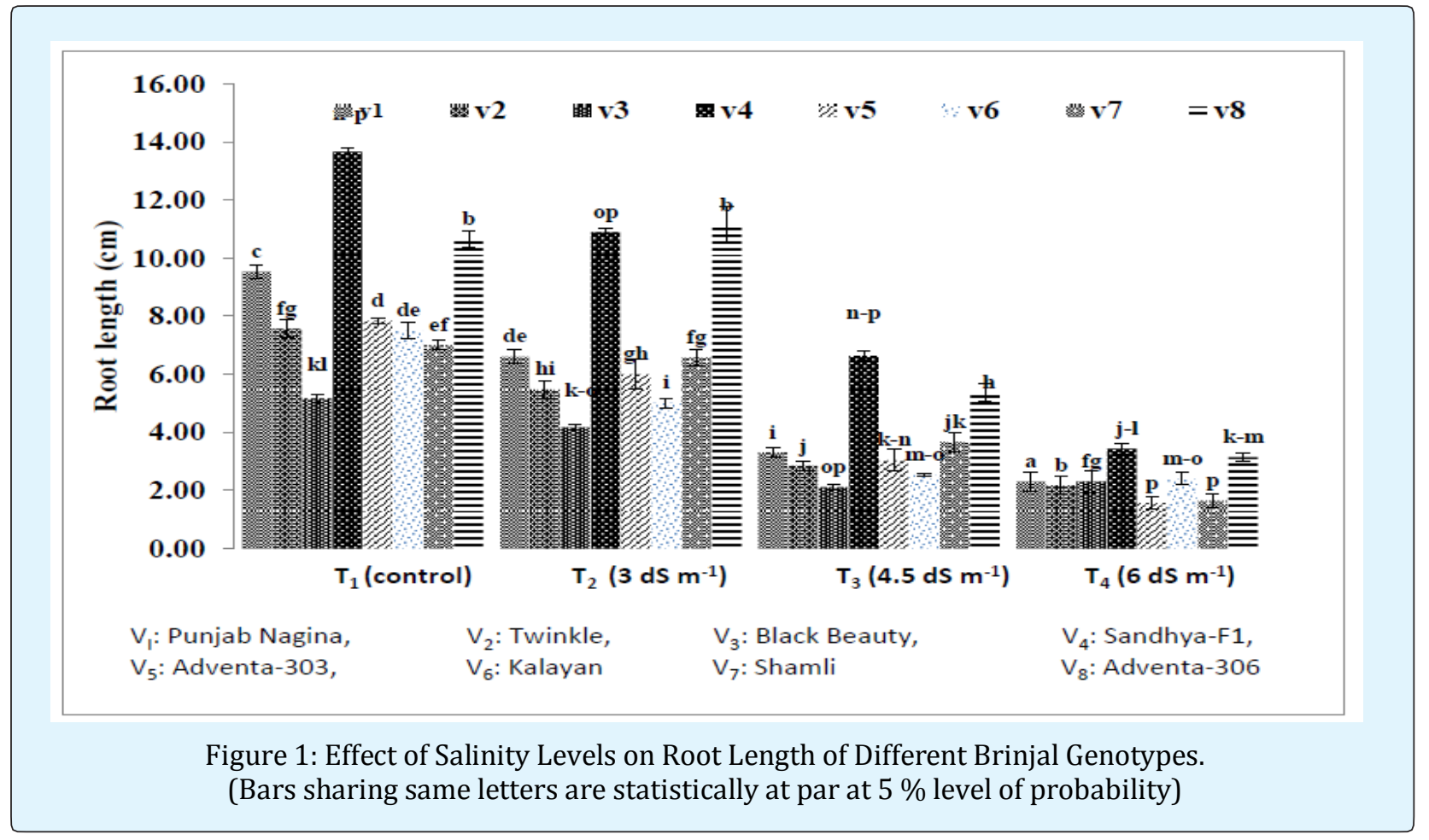

Riaz U, et al. Screening of Brinjal (Solanum Melongena L.) Genotypes against 


\section{Food Science and Nutrition Technology}

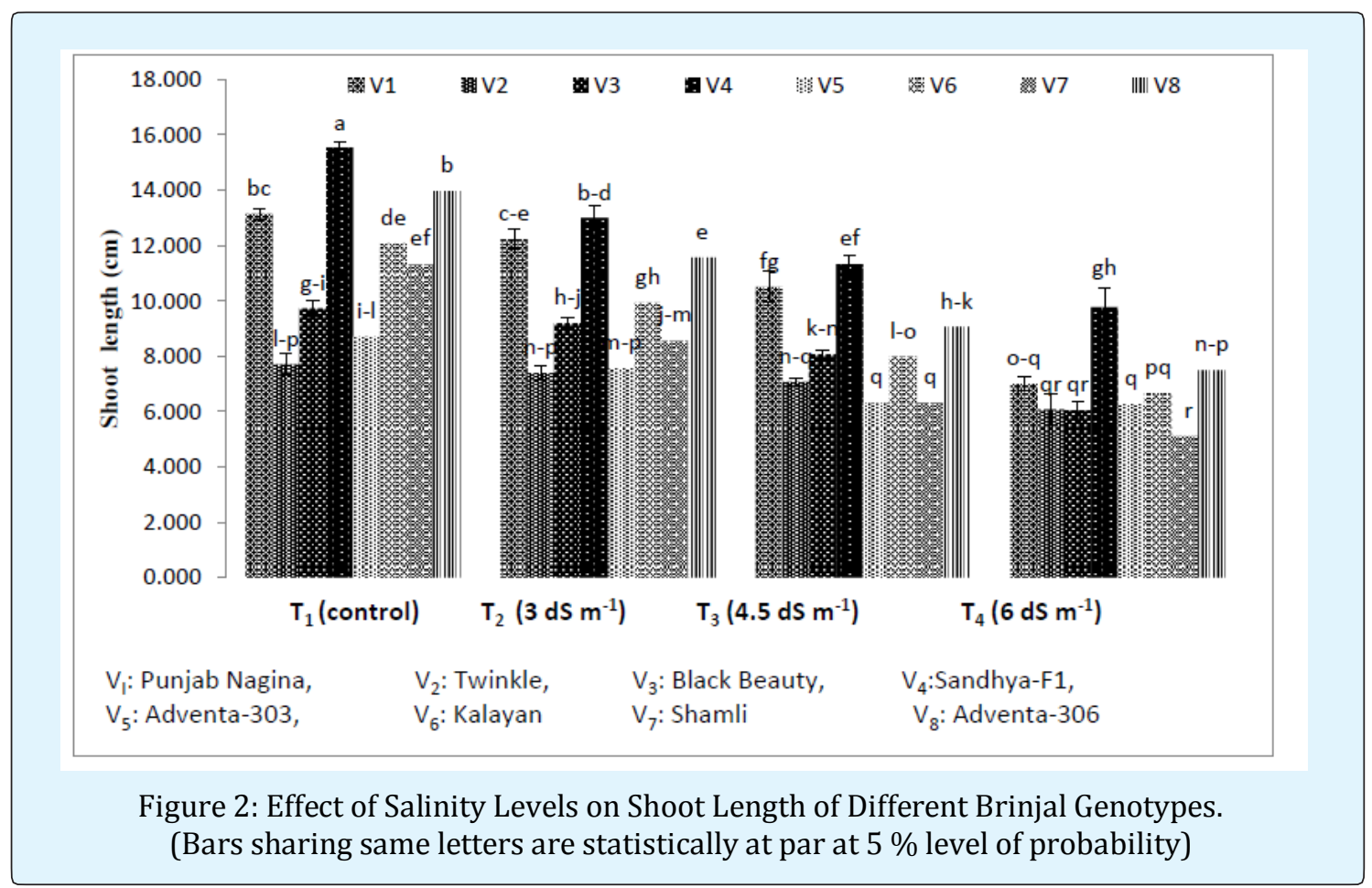

\section{Root and Shoot Fresh Weight}

On the basis of results of present study, it is concluded that salinity tolerance mechanism altered according to the tolerance ability of the genotype. As the salinity level increased, different genotypes showed significant results. Analysis of variance showed that all the tested genotypes show reduction in plant fresh and dry biomass. But the genotypes "Sandhya F1" and "Adventa 306" showed maximum tolerance. In term of having least reduction in plant fresh weight genotype "Sandhya F1" and "Adventa 306" show maximum tolerance potential at all salinity level ( $3 \mathrm{dS} \mathrm{m}^{-1}, 4.5 \mathrm{dS} \mathrm{m}^{-1}, 6 \mathrm{dS} \mathrm{m}^{-1}$ ) (Figures $3 \& 4$ ).

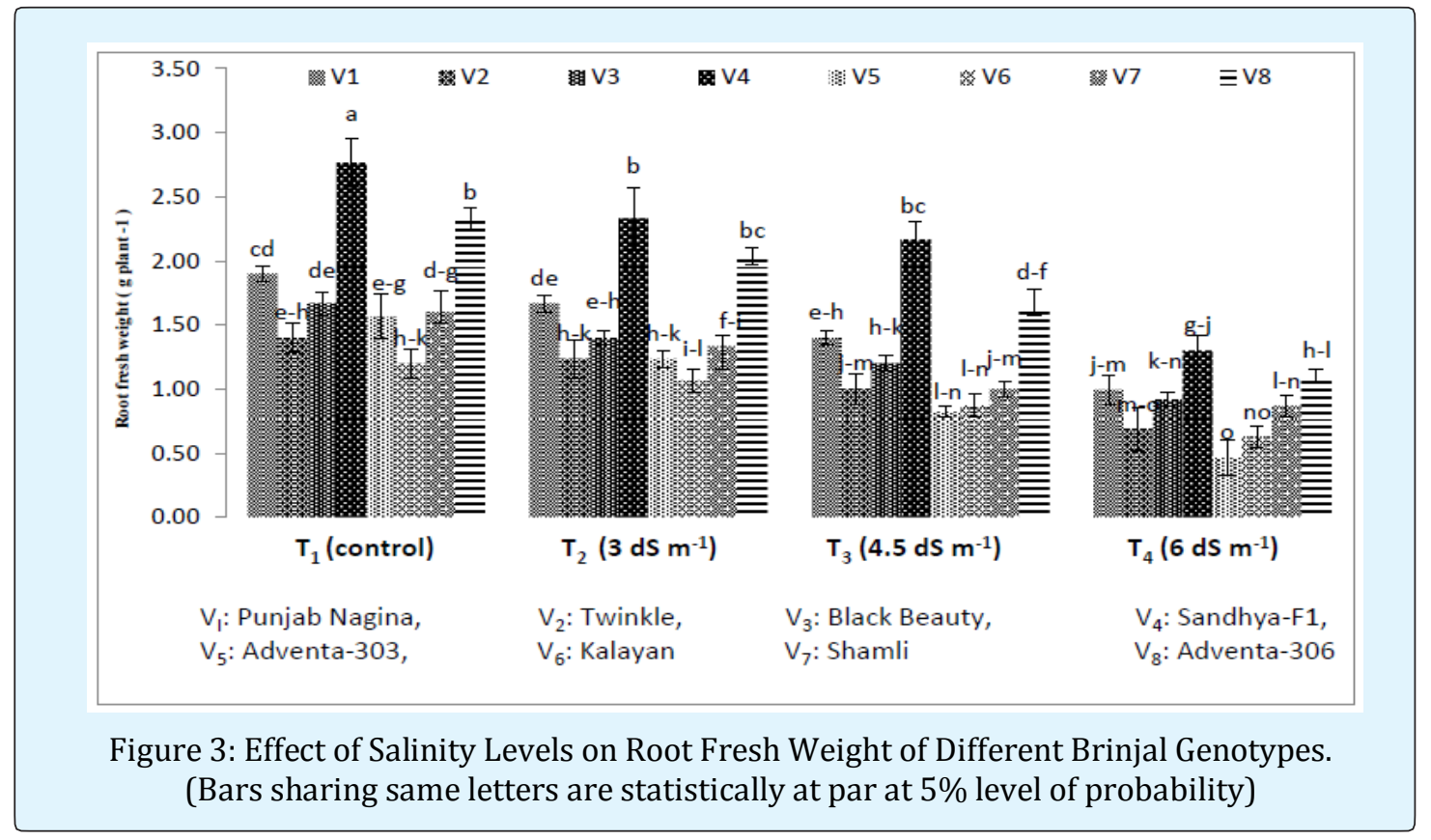

Riaz U, et al. Screening of Brinjal (Solanum Melongena L.) Genotypes against 


\section{Food Science and Nutrition Technology}

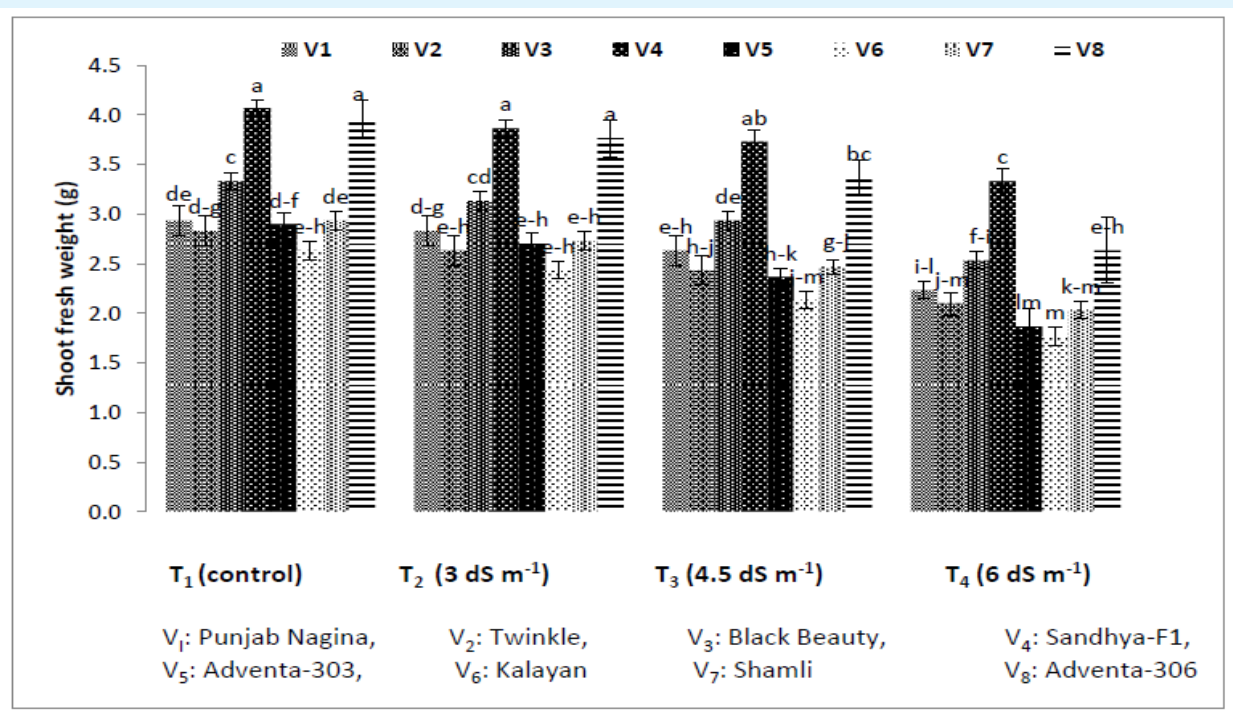

Figure 4: Effect of Salinity Levels on Shoot Fresh Weight of Different Brinjal Genotypes.

(Bars sharing same letters are statistically at par at 5\% level of probability)

Similarly plant dry weight was also reduced when plant was subjected to salt stress. Maximum reduction was caused by $6 \mathrm{dS} \mathrm{m}^{-1}$ as compare to $3 \mathrm{dS} \mathrm{m}^{-1}$ and $4.5 \mathrm{dS} \mathrm{m}^{-1}$ (Figures $5 \& 6$ ). The genotype which response as minimum reduction in plant fresh and dry weight were categorized as salt tolerant and those show maximum reduction were categorized as salt sensitive genotype. This result is in agreement with Unlukara, et al. [20] who describe that the increase in salinity level decreases the plant fresh and dry biomass due to less availability of mineral nutrition. Andriolo, et al. [21] observed a positive effect of low EC on shoot fresh mass of lettuce.

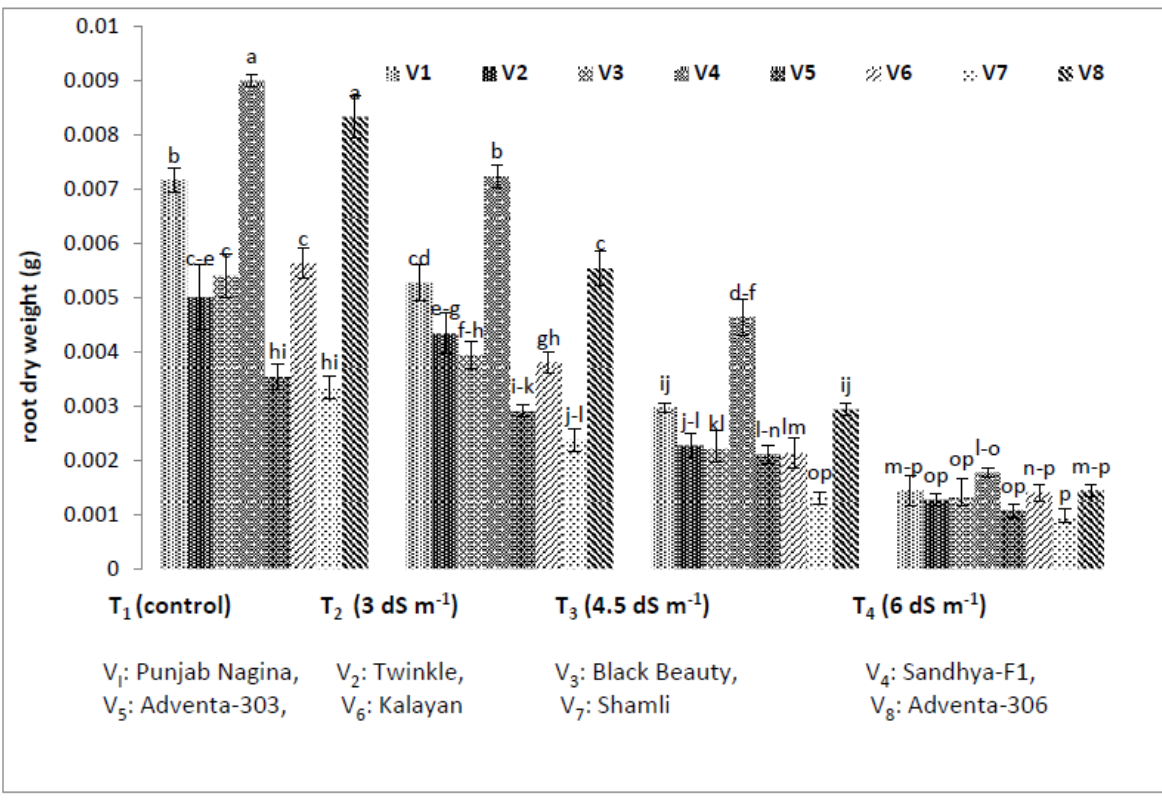

Figure 5: Effect of Salinity Levels on Root Dry Weight of Different Brinjal Genotypes.

(Bars sharing same letters are statistically at par at $5 \%$ level of probability) 


\section{Food Science and Nutrition Technology}

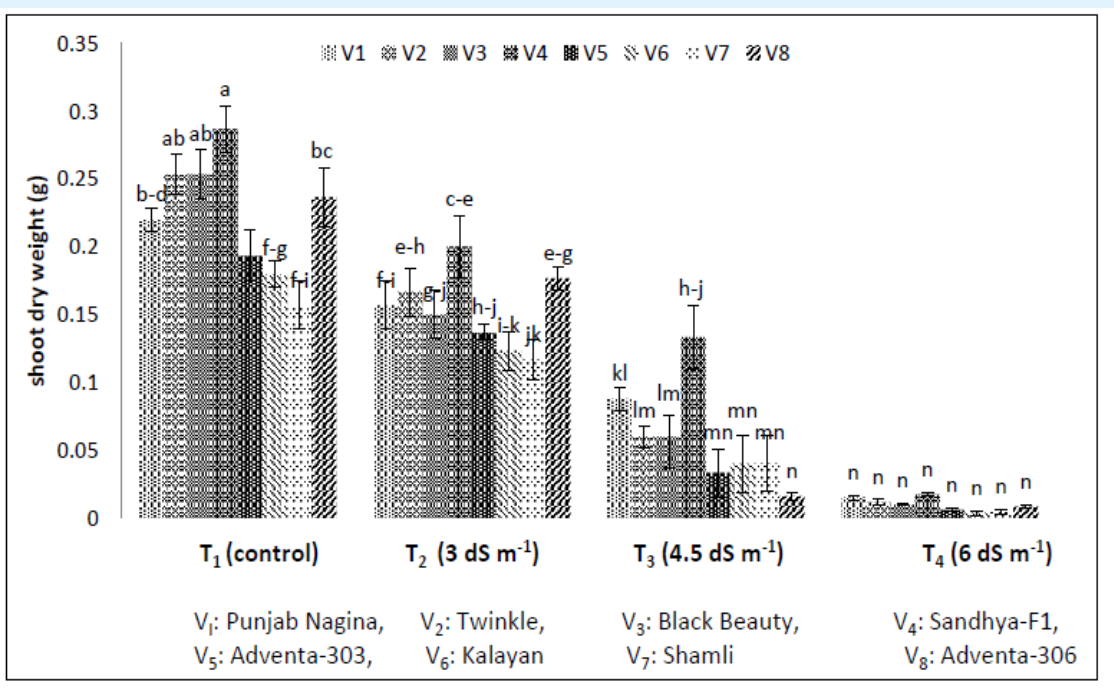

Figure 6: Effect of Salinity Levels on Shoot Dry Weight of Different Brinjal Genotypes. (Bars sharing same letters are statistically at par at $5 \%$ level of probability)

\section{Physiological Attributes}

Salinity is a major factor that reduces plant growth. In this study salinity stress significantly reduces the photosynthetic activity by disturbing the plant internal mechanisms. Salinity affects the normal mechanism of plant. At highest level $\left(\mathrm{T}_{4}\right)$ of stress all genotypes showed the maximum sensitivity against salinity and cannot withstand for further growth as compare to the rest of treatments. In salinity free treatment $\left(\mathrm{T}_{1}\right)$, membrane stability index was maximum in all genotypes in comparison to other treatments (Figure 7).

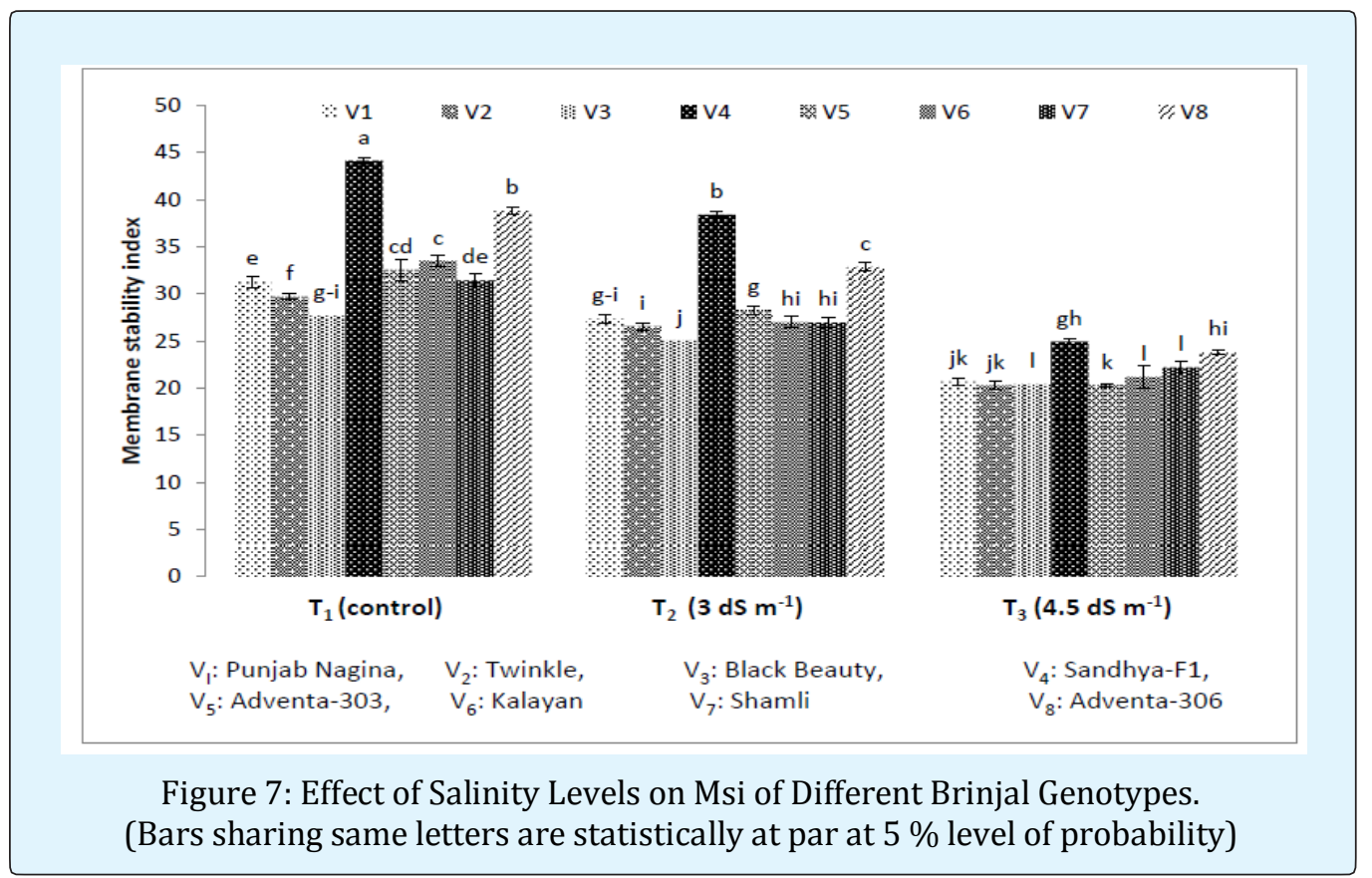

Riaz U, et al. Screening of Brinjal (Solanum Melongena L.) Genotypes against 


\section{Food Science and Nutrition Technology}

$\mathrm{Wu}$, et al. [22] also concluded that increasing stress level decreases the photosynthetic activity and ultimately chlorophyll contents. Wu, et al. [17] also describe that increasing $\mathrm{NaCl}$ treatment level significantly decline the chlorophyll "a", "b" and carotenoid contents in different brinjal genotypes according to their sensitivity. Siddiqi, et al. [23] found that reduction in chlorophyll $a$ and $b$ under salinity stress was might be due to decrease in chlorophyll contents. The physiological traits including membrane stability index (MSI) (Figure 7), carotenoids (Figure 8), chlorophyll a (Figure 9) and chlorophyll b (Figure 10) were severely influenced by salinity stress and lower values were recorded in salinity treatments. Similar results were found by Akram, etal. (2012) [24] in sunflower and by Abbasi, et al. (2014) [25] in maize crop.

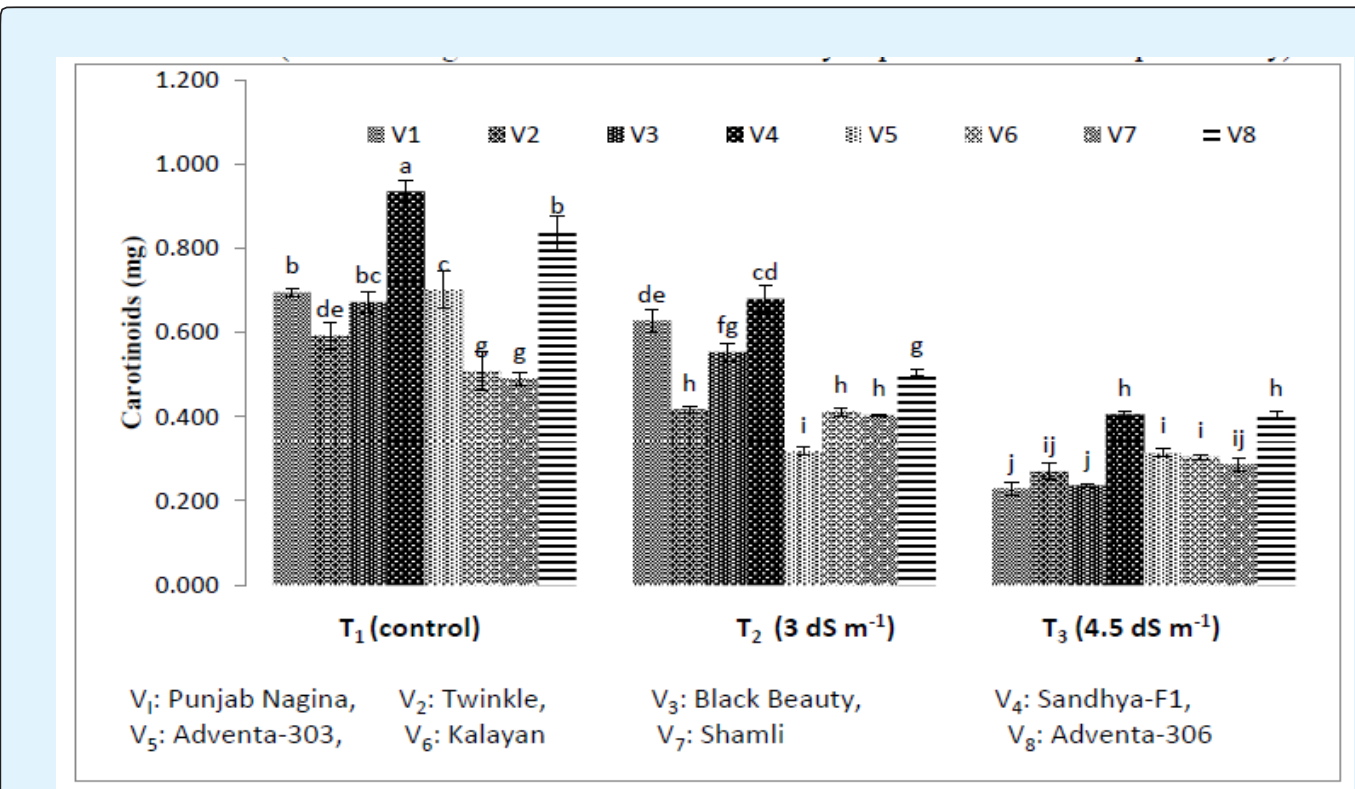

Figure 8: Effect of Salinity Levels on Carotenoid Contents of Different Brinjal Genotypes.

(Bars sharing same letters are statistically at par at $5 \%$ level of probability)

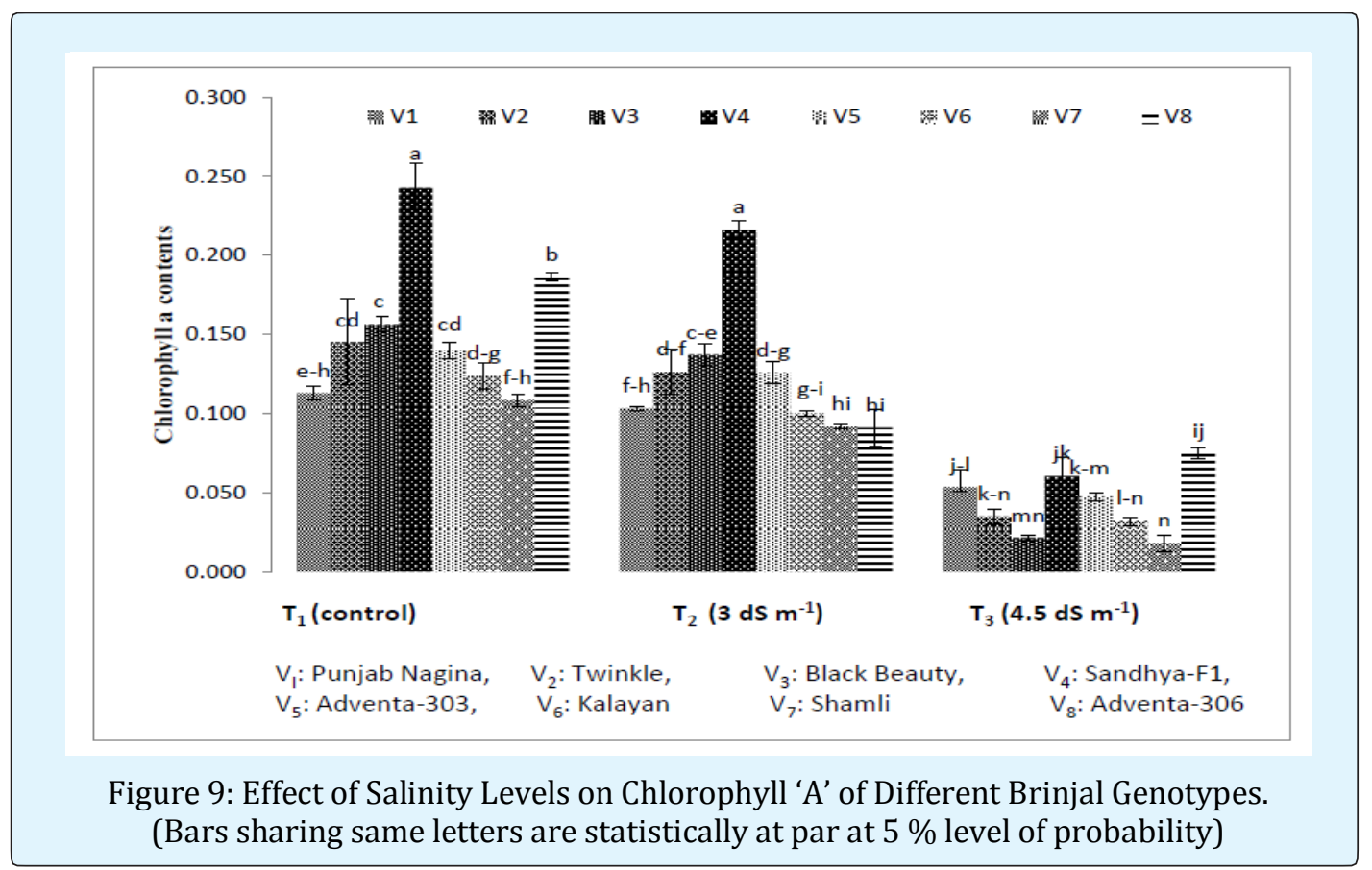

Riaz U, et al. Screening of Brinjal (Solanum Melongena L.) Genotypes against Salinity. Food Sci Nutr Technol 2018, 3(2): 000146. 


\section{Food Science and Nutrition Technology}

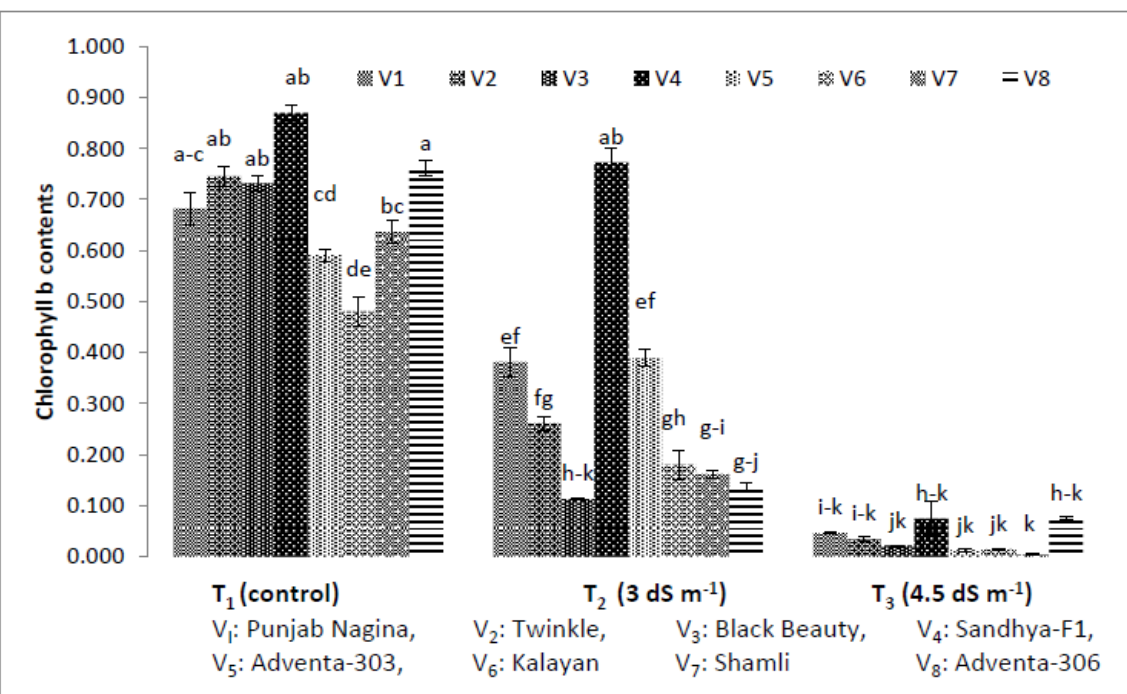

Figure 10: Effect of Salinity Levels on Chlorophyll 'B' Of Different Brinjal Genotypes. (Bars sharing same letters are statistically at par at $5 \%$ level of probability)

\section{Ionic attributes}

When treated with different $\mathrm{NaCl}$ doses brinjal seedlings accumulate remarkable concentration of $\mathrm{Na}$ in root (Figure 11) and as well as in shoot (Figure 12). In salinity free treatment less amount of $\mathrm{Na}$ accumulation was recorded among all genotypes while the accumulation pattern of $\mathrm{Na}$ was found to be proportional to the $\mathrm{Na}$ application. At higher level $\left(\mathrm{T}_{4}\right)$ where maximum concentration of $\mathrm{Na}$ was applied $\left(6 \mathrm{dS} \mathrm{m}^{-1}\right)$, the highest root sodium concentration was recorded. The resistant variety Sandhya-F1 showed least accumulation in root and shoot as compare to other genotypes. While the genotype Kalyan showed the maximum sensitivity and higher accumulation of salts. Maathuis [26] describe that sodium uptake and accumulation is directly proportional to the transpiration rate. Similarly, in another experiment, it was revealed that salt stress caused a marked decrease in $\mathrm{K}^{+}$content, while increased $\mathrm{Na}^{+}$and $\mathrm{Cl}^{-}$contents in eggplants [20].

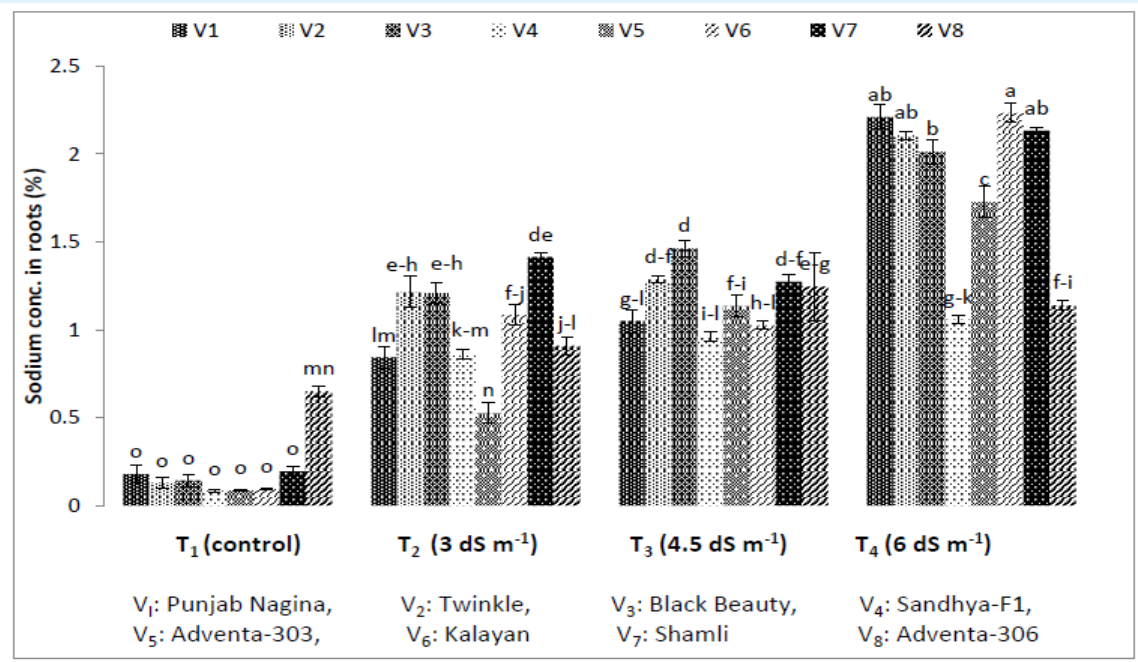

Figure 11: Effect of Salinity Levels on Root $\mathrm{Na}^{+}$Concentration of Different Brinjal Genotypes. (Bars sharing same letters are statistically at par at $5 \%$ level of probability) 


\section{Food Science and Nutrition Technology}

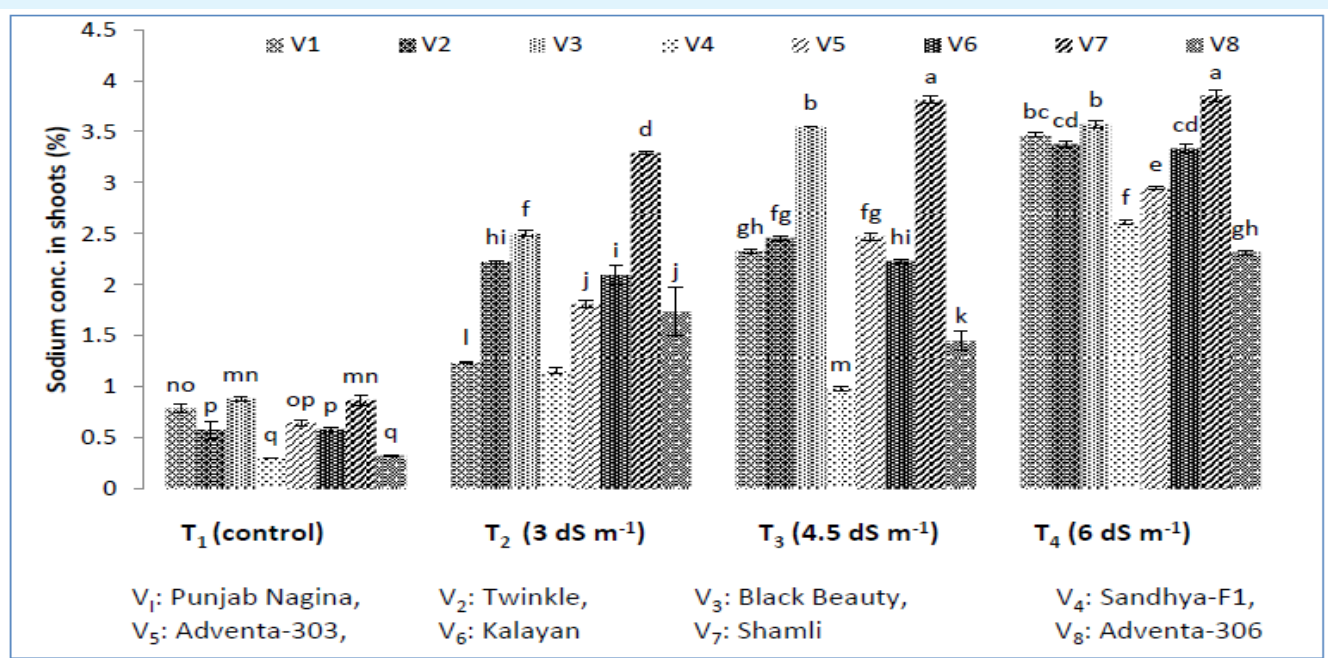

Figure 12: Effect of Salinity Levels on Shoot $\mathrm{Na}^{+}$Concentration of Different Brinjal Genotypes. (Bars sharing same letters are statistically at par at $5 \%$ level of probability)

\section{Potassium Concentration in Root and Shoot}

From the results it is revealed that potassium concentration decreased in rhizosphere as the sodium concentration increased and this reduction was higher in shoots of plants at $6 \mathrm{dS} \mathrm{m}^{-1}$ (Figure 13).

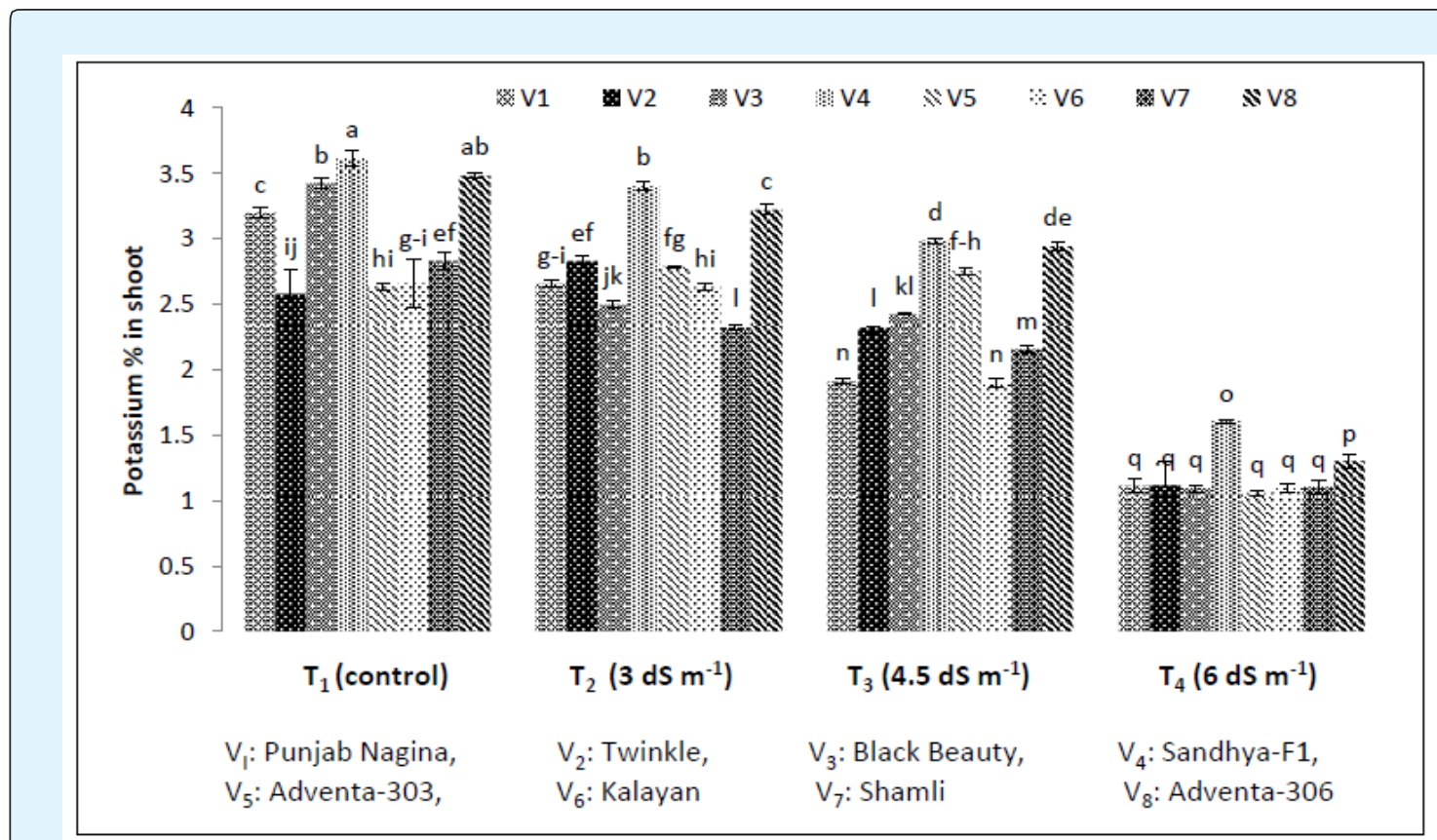

Figure 13: Effect of Salinity Levels on Shoot $\mathrm{K}^{+}$Concentration of Different Brinjal Genotypes. (Bars sharing same letters are statistically at par at $1 \%$ level of probability) 


\section{Food Science and Nutrition Technology}

Under controlled condition, when no $\mathrm{NaCl}$ was given $\left(\mathrm{T}_{1}\right)$, maximum amount of $\mathrm{K}^{+}$was found in all genotypes. The concentration pattern of $\mathrm{K}^{+}$was observed to be proportional to the $\mathrm{Na}^{+}$accumulation. At highest salinity level $\left(\mathrm{T}_{4}\right)$ where higher dose of $\mathrm{Na}$ was applied $\left(6 \mathrm{dS} \mathrm{m}^{-1}\right)$, the lowest concentration of potassium was observed in roots (Figure 14). The genotype Sandhya-F1 showed the maximum concentration of $\mathrm{K}^{+}$while sensitive variety Adventa-303 showed minimum. Sairam, et al. [27] reported that by increasing salinity a decrease in shoot $\mathrm{K}^{+}$ concentration was also observed. To counter act salt stress plants have develop mineral ion homeostasis [28].

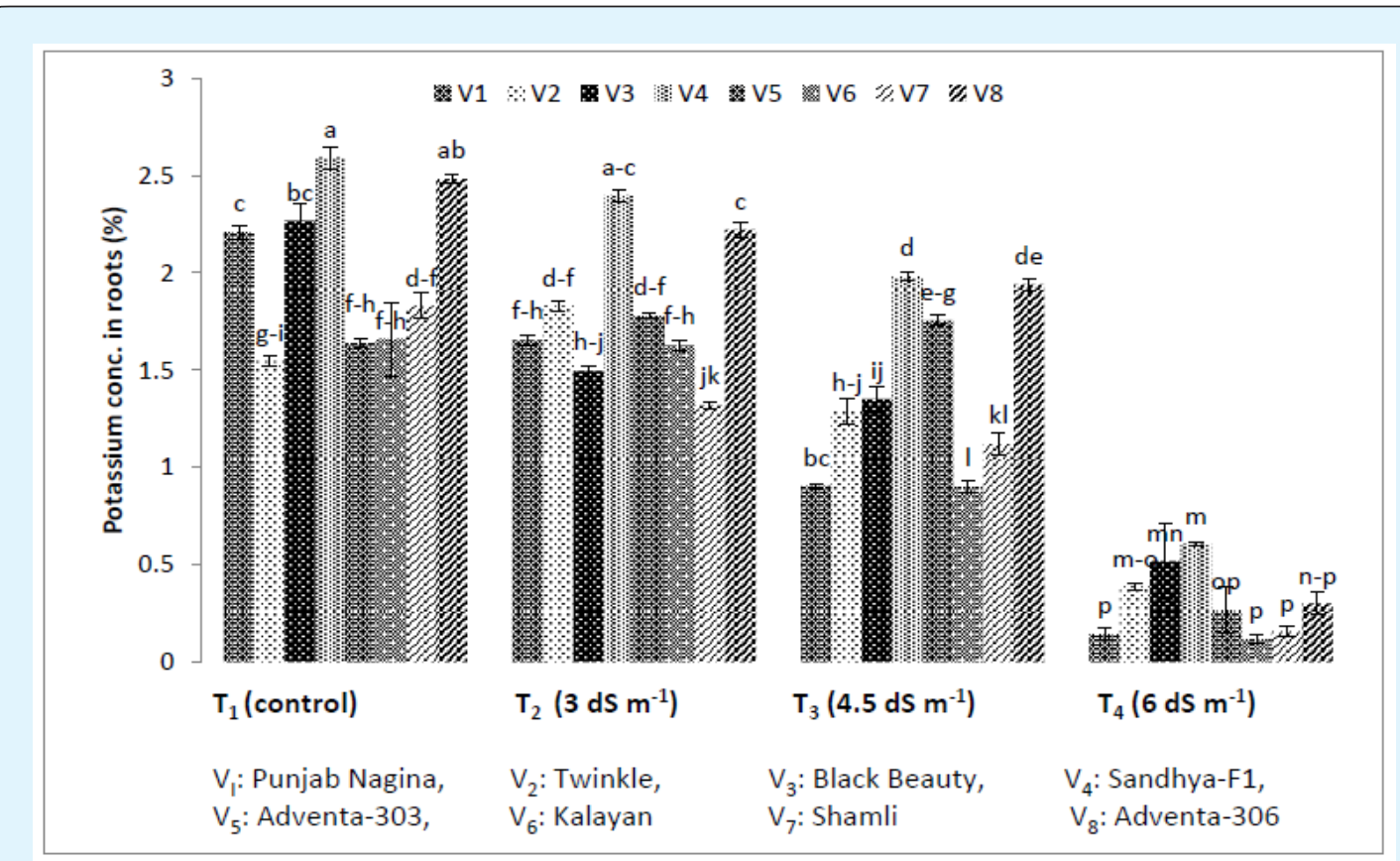

Figure 14: Effect of Salinity Levels on Root $\mathrm{K}^{+}$Concentration of Different Brinjal Genotypes. (Bars sharing same letters are statistically at par at $1 \%$ level of probability)

\section{Conclusion}

This experiment showed that brinjal was adversely affected by increase in salt concentration at the seedling and vegetative growth stages. Sandhya F1 showed successful results than the other varieties at seedling and vegetative growth stages. Determination of salt tolerance of brinjal genotypes was significant in the seedling and growth stage, as salinity showed the most harmful effects in these stages. As the plant gained maturity, salt tolerance increased. It is very important in agricultural production to prevent salt from negatively affecting germination and seedling stages. This study indicated that salt tolerance of eggplant varieties varied as the plants matured.

\section{Acknowledgment}

We are highly thankful to Department of Soil Science, University College of Agriculture and Environmental
Science, The Islamia University of Bahawalpur for providing the field area and laboratory facilities to complete the research.

\section{References}

1. Ladeiro B (2012) Saline agriculture in the $21^{\text {st }}$ century: using salt contaminated resources to cope food requirements. Journal of Botany 2012: 310705.

2. Vahdati N, Tehranifar A, Neamati SH, Selahvarzi Y (2012) Physiological and Morphological responses of white clover (Trifolium repens) and red clover (Trifolium pratense) plants to salinity stress. J Orna Horti Plants 2(4): 233-241.

3. Misra N, Saxena P (2009) Effect of salicylic acid on proline metabolism in lentil grown under salinity stress. J Plant Sci 177(3): 181-189. 


\section{Food Science and Nutrition Technology}

4. Naim MA (2016) Mitigation of salt stress in rice by exogenous application of selenium (Doctoral dissertation).

5. Zhu JK (2003) Regulation of ion homeostasis under salt stress. Curr Opin Plant Biol 6(5): 441-445.

6. Rozentsvet OA, Nesterov VN, Bogdanova ES (2017) Structural, physiological, and biochemical aspects of salinity tolerance of halophytes. Russ J Plant Physiol 64(4): 464-477.

7. Dunlop F (2006) Revolutionary Chinese cookbook. Recipes from Hunan Province, Ebury Pess.

8. Stewart GF, Amerine MA (2012) Introduction to food science and technology. Elsevier.

9. Fao I, Isric I (2012) JRC: Harmonized World Soil Database (version 1.2). FAO, Rome, Italy and IIASA, Laxenburg, Austria.

10. Yousafi Q Afzal M, Aslam M, Razaq M, Shahid M (2013) Screening of brinjal (Solanum melongena L.) varieties sown in autumn for resistance to cotton jassid, Amrasca bigutulla bigutulla (Ishida). Pak J Zool 45(4): 897-902.

11. Saboora A, Kiarostami K, Behroozbayati F, Hajihashemi S (2006) Salinity ( $\mathrm{NaCl})$ tolerance of wheat genotypes at germination and early seedling growth. Pak J Biol Sci 9(11): 2009-2021.

12. Aghaei K, SKomatsu S (2013) Crop and medicinal plants proteomics in response to salt stress. Front Plant Sci 4: 8.

13. Singh UM, Sareen P, Sengar RS, Kumar A (2013) Plant ionomics: a newer approach to study mineral transport and its regulation. Acta physiologiae plantarum 35(9): 2641-2653.

14. Londhe S (2016) Sustainable Potato Production and the Impact of Climate Change. IGI Global.

15. Upadhyay SK, Singh JS, Saxena AK, Singh DP (2012) Impact of PGPR inoculation on growth and antioxidant status of wheat under saline conditions. Plant Biol 14(4): 605-611.

16. Shahbaz M, Mushtaq Z, Andaz F, Masood A (2013) Does proline application ameliorate adverse effects of salt stress on growth, ions and photosynthetic ability of eggplant (Solanum melongena L.)?. Sci Hort 164: 507-511.

17. Wu X, He J, Chen J, Yang S, Zha D (2014) Alleviation of exogenous 6-benzyladenine on two genotypes of eggplant (Solanum melongena Mill.) growth under salt stress. Protoplasma 251(1): 169-176.

18. Navarro A, Bañón S, Conejero W, Sánchez-Blanco MJ (2008) Ornamental characters, ion accumulation and water status in Arbutus unedo seedlings irrigated with saline water and subsequent relief and transplanting. Environ Exper Bot 62(3): 364-370.

19. Gao X, Zou C, Wang L, Zhang F (2006) Silicon decreases transpiration rate and conductance from stomata of maize plants. J. Plant Nutr 29(9):16371647.

20. Unlukara A, Kurunç A, Kesmez GD, Yurtseven E, Suarez DL (2010) Effects of salinity on eggplant (Solanum melongena L.) growth and evapotranspiration. J Irrig Drain Eng 59(2): 203-214.

21. Andriolo JL, Luz GLD, Witter MH, Godoi RDS, Barros GT, et al. (2005) Growth and yield of lettuce plants under salinity. Hortic Bra 23(4): 931-934.

22. Wu X, Zhu Z, Li X, Zha D (2012) Effects of cytokinin on photosynthetic gas exchange, chlorophyll fluorescence parameters and antioxidative system in seedlings of eggplant (Solanum melongena L.) under salinity stress. Acta physiologiae plantarum 34(6): 2105-2114.

23. Siddiqi EH, Ashraf M, Hussain M, Jamil A (2009) Assessment of intercultivar variation for salt tolerance in safflower (Carthamus tinctorius L.) using gas exchange characteristics as selection criteria. Pak J Bot 41(5): 2251-2259.

24. Akram NA, Ashraf M, Al-Qurainy F (2012) Aminolevulinic acid-induced changes in some key physiological attributes and activities of antioxidant enzymes in sunflower (Helianthus annuus L.) plants under saline regimes. Sci Hort 142: 143-148.

25. Abbasi GH, Akhtar J, Anwar-ul-Haq M, Ali S, Chenand $\mathrm{Z}$, et al. (2014) Exogenous potassium differentially mitigates salt stress in tolerant and sensitive maize hybrids. Pak J Bot 46: 135-146. 


\section{Food Science and Nutrition Technology}

26. Maathuis FJ (2013) Sodium in plants: perception, signaling, and regulation of sodium fluxes. J Exp Bot 65(3): 849-858.

27. Sairam RK, Rao KV, Srivastava GC (2002) Differential response of wheat genotypes to long term salinity stress in relation to oxidative stress, antioxidant activity and osmolyte concentration. Plant Sci 163(5): 1037-1046.

28. Sairam RK, Srivastava GC, Agarwal S, Meena RC (2005) Differences in antioxidant activity in response to salinity stress in tolerant and susceptible wheat genotypes. Biol Plant 49(1): 85-91. 